\title{
Safety Assessment of High-Risk Operations in Hydroelectric-Project Based on Accidents Analysis, SEM, and ANP
}

\author{
Jian-Lan Zhou, ${ }^{1}$ Bai Zhe-Hua, ${ }^{1}$ and Zhi-Yu Sun ${ }^{2}$ \\ ${ }^{1}$ Key Laboratory of Ministry of Education for Image Processing and Intelligent Control, Department of Systems Science and Engineering, \\ Huazhong University of Science \& Technology, Wuhan, Hubei 430074, China \\ ${ }^{2}$ Departments of Science, Technology \& Environmental Protection, China Three Gorges Project Corporation, Beijing 100038, China
}

Correspondence should be addressed to Jian-Lan Zhou; zhouj11999@163.com

Received 20 August 2013; Accepted 1 October 2013

Academic Editor: Zhiguang Feng

Copyright (C) 2013 Jian-Lan Zhou et al. This is an open access article distributed under the Creative Commons Attribution License, which permits unrestricted use, distribution, and reproduction in any medium, provided the original work is properly cited.

Safety risk analysis and assessment of high-risk work system in hydroelectric project has an important role in safety management. The interactive relationships between human factors and the importance of factors are analyzed and proposed. We analyze the correlation relationship among the factors by using statistical method, which is more objective than subjective judgment. The HFACS is provided to establish a rational and an applicable index system for investigating human error in accidents; the structural equation modeling (SEM) and accident data are used to construct system model and acquire the path coefficient among the risk factor variables; the ANP model is built to assess the importance of accident factors. 289 pieces of valid questionnaires data are analyzed to obtain the path coefficient between risk factor variables and to build the ANP model's judgment matrix. Finally, the human factors' weights are calculated by ANP model. Combining SEM's results and factor's frequency analysis and building the ANP model, the results show that the four greatest weight values of the factors are, respectively, "personal readiness," "perception and decision errors," "skill-based errors," and "violation operations." The results of ANP model provide a reference for the engineering and construction management.

\section{Introductions}

Hydroelectric project construction has higher safety risk for the interactive factors like complex geological conditions, small venue, large amount of construction workers, various stages of cross-operation, and frequent aerial work, which is vulnerable to induce safety accidents. In recent years, in order to guarantee the safety of hydroelectric project construction work, a great deal of human, material, and financial resources have been invested, the management and supervision of construction have gradually strengthened, but the overall status remains grim, and the annual total number of hydroelectric project construction accidents and the number of deaths and serious injuries are still high in China. The safety work management is still in a blind state; especially the role of human factors in the accident control still lacks clarity. In order to create a good work environment and improve the safety index of the hydroelectric project construction, we need to find out the safety factors in construction, implement identification of human risk factors, analyze interrelationship between human factors, calculate the weight of every factors, find out the factors need to improve, and minimize or prevent the occurrence of accidents.

In hydroelectric project construction process, a significant proportion of the technical causes of serious accidents are attributed to human factors, to establish a rational and comprehensive safety classification system based on human behavior is important for safety assessment. The classification system is used to provide the types of failure involved in accidents. One of the more widely used approaches is the Human Factors Analysis and Classification System [1] drawn in [2]. HFACS is a commonly utilized tool for investigating human contributions to aviation accidents under a 
widespread evaluation scheme. HFACS, and its derivatives, has been adapted, applied, and promoted in several domains (and countries) in addition to commercial and private flying, including mining accident $[3,4]$, helicopter maintenance [5], maritime accident $[6,7]$, railroad accident $[8]$, and surgery accident [9]. In [6], the HFACS was extended on an analytical basis in a fuzzy environment to investigate shipping accidents in a consistent manner. A sample of 263 significant mining incidents in Australia across 2007-2008 are analyzed using HFACS and provide a greater understanding of the systemic factors involved in mining accidents [3]. Therefore, we extend the HFACS on an analytical basis in the safety assessment of work system in hydropower project construction to evaluate the faulty behavioral risk value.

In HFACS framework extended for hydroelectric project construction, there are some observed factors and latent factors; some of these are influenced by each other; quantitative analysis on these factors to assess their weight in whole system is needed. Structural equation modeling (SEM) is a modeling technique that can handle a large number of endogenous and exogenous variables, as well as latent (unobserved) variables specified as linear combinations (weighted averages) of the observed variables. Regression, simultaneous equations (with and without error-term correlations), path analysis, and variations of factor analysis and canonical correlation analysis are all special cases of SEM [10]. We can consider the risk as a quantity, which can be measured and expressed by a mathematical relation, under the help of real accidents' data [11-13]. SEM is a relatively new method, and its history can be traced back to the 1970 s. Most applications have been in psychology, sociology, the biological sciences, educational research, political science, and market research. Applications in travel behavior research date from 1980. Use of SEM is now rapidly expanding as userfriendly software becomes available, and researchers become comfortable with SEM and regard it as another tool in their arsenal. Chen et al. [14] research the influencing factors of coalmine employees' deliberate violation behaviors in China coalmine fatal accidents.

There are some evaluation methods for hydroelectric project high-risk operations, such as LEC assessment method, Safety Inspection Table, Analytic Hierarchy Process (AHP), Fault Tree Analysis method, Fuzzy Comprehensive Evaluation method, and Neural Network. Many scholars over the world have researched in this area. In [15], the degree of danger was studied when the workers work in potentially dangerous environment, presented the LEC method's formula $D=L * E * C$, where $D$ is the value-atrisk, $L$ is the probability of the accident happening, $E$ is how often exposure to dangerous environment, and $C$ is the possible consequences of the accident. LEC method is greatly dependent on the subjectivity of experts, which is prone to difference in the process of rating value; the results are not very objective. Dongzhi [16] used Accident Tree Analysis, studied risk factors of hydroelectric engineering construction, put forward improvement measures to reduce the incidence of accidents, and improved the safety level of construction. But Accident Tree Analysis method has many calculation steps and is difficult to make quantitatively analysis when the data are less. Dedobbeleer and Béland [17] identified the current safety performance evaluation index of construction work system, understood the practical characteristics of workplace by questionnaire survey, and accordingly analyzed construction of safety environment. In $[18,19]$, safety warnings were proposed after certain steps, including identification of factors which can influence safety level, assessment of potential changes of those factors, assessment of the impact of those changes and selection of safety-related criteria.

The above studies adopt different evaluation methods to analyze the project safety, but there is no evaluation from a holistic perspective; all the methods have some deficiencies. Application of Analytic Network Process (ANP) in the project construction for safety assessment is a hotspot; this is a method based on Analytic Hierarchical Process (AHP). ANP method considers interrelationship among all factors in the same level and adjacent levels, uses supermatrix to comprehensively analyze the factors affecting each other, and obtains the ultimate hybrid weight. In dealing with complex problems that elements connected with and influenced each other, ANP method is proved to be effective and reasonable by the global studies. In [20], fuzzy ANP method was adopted to evaluate the operation system's risk factors, but the correlations among the factors are simply used by the experts' estimation, which may induce expert's bias. In [21], the “ $3 \mathrm{P}+$ I" model was proposed to evaluate the effectiveness of safety management system, AHP and factor analysis were used to identify the key indicators impacting the construction and eventually the questionnaire and expert scoring method were adopted to determine the weight. In [22] the hydroelectric project risk factors were studied to establish the index system based on the ANP, and five main classes of risk factors were identified: organization and management of risks, technological risks, natural risks, social risk, and economic risk and actually a hydroelectric project was assessed. In contrast with the above studies, there is a little research on hydroelectric project construction, or it only uses a single method to qualitatively analyze correlation coefficient and may cause subjective influence. In [23], it was noted noted that the ANP method has some limitations, cannot exclude the bias of the experts, the model's output depends on the given value of expert and cause inconsistencies in the pairwise comparison process. Therefore, it was mentioned that knowledge should be incorporated. In [24], it was pointed out should make use of statistical methods for the analysis of accident statistics, so as to more accurately determine dependency relationship between elements, which avoid the comparison between factors given by experts with prejudice or inconsistency problem.

Therefore, it is necessary to use ANP method combined with quantitative methods and systematically study the factors from the layers of management to construction workers. Combining ANP and other methods for comprehensive assessment can take advantage of their respective advantages, 
develop its advantages, avoid disadvantages, and get better results. In [25], ANP and Bayesian Networks method were used to study the safety classification of nuclear power plants. In [26], the ANP and DEMATEL were combined successfully to solve the evaluation for vehicle fleet maintenance management. In [27], QFD, fuzzy ANP, and fuzzy FMEA (failure modes and effect analysis) were used to identify the important types and causes of hazards in the construction industry, meantime providing risk assessment values of hazard causes and relevant improvement strategies. Above researches combined ANP with other methods, the evaluation process is becoming more refined and more realistic. In this paper, we combined ANP, HFACS, SEM, and synthetic statistical methods to evaluate the high-risk work system in hydroelectric projects.

The rest of this paper is organized as follows. In Section 2, the framework of research methodology is constructed and has been presented in detail. In Section 3, based on the HFACS framework, the questionnaire is designed and SEM is built by AMOS. Section 4 analyzes the correlation factors' interdependence relationships based on accident cases by lambda method and tau-y method. In Section 5, the relative weights of factors are calculated by synthetic matrix in ANP model. Finally, the results were thoroughly analyzed, while in the last section the main conclusions and future research topics were drawn up.

\section{Methodology Research}

ANP model is based on risk influential factors' classification and layered architecture. This study firstly analyzes the human risk factors; therefore, human factors analysis and classification system framework (HFACS) is used to analyze human factors in construction engineering accidents. The technical thinking of this study is firstly applying HFACS and other standardized documents or results to design questionnaire, which is designed for the Three Gorges project, and Xiluodu project, Xiangjiaba project, and then sends the questionnaire to the management units, design units, construction units, supervision units, and technical and safety management staff. Secondly, we analyze the questionnaire data; SPSS17.0 can analyze reliability and validity of the data and confirm the internal consistency of the data. If the data's reliability is high, use AMOS to establish structural equation modeling (SEM); the path coefficients among the factors can be obtained, thus the relationship can be analyzed among the factors. Thirdly, under the HFACS, structure the previous accident cases of Xiluodu project, Xiangjiaba project, and the Three Gorges project, using statistical methods to analyze human factors of accident, we can get the correlation coefficient between the factors. Finally, based on the preceding analysis, combine judgment matrix achieved by empowerment table with judgment matrix by SEM, use linear weighting method, obtain one synthesized judgment matrix, and then calculate this judgment matrix by Super Decision (SD) tool. Eventually, we obtain the ANP evaluation weight and ranking of various factors. In summary, this study was carried out through interviews, questionnaires, theoretic analysis with modeling and statistic methods, and decision and assessment method. It consists of 3 stages shown in Figure 1.

\section{Factors Correlation Analysis Based on Empirical Study}

3.1. HFACS Framework. Before designing the questionnaire, firstly make sure of the composition of hydroelectric construction risk factors, determine the classification and hierarchical structure of human factors, and construct hierarchy model of hydroelectric construction risk; then base on the model to implement the study. In this study, the HFACS framework is adopted to analyze the human factors which result in the engineering construction accidents; HFACS considers both unsafe behaviors and potential factors which influence unsafe behaviors, satisfy the characteristics of reliability, diagnostic and comprehensive, in accidents investigation. We revise the standard framework of HFACS to adapt with actual safety management of hydroelectric project construction, technical measurements, personnel quality situation, and so forth; the adjusted risk influential human factor is shown in Figure 2.

3.2. Questionnaire Design. In the HFACS framework shown in Figure 1, there are 4 categories and 17 indicators of human factors in this study. We finally formed a questionnaire with 63 detailed items, which include 9 items about organizational influences, 24 items about safety management, 23 items about site work related factors, and 7 items about construction personal unsafe behaviors. According to the degree of importance, the questionnaire's indicators are in descending order and adopt Likert-3 table scale method to divide indictors into three degrees: "the first class indicator," scheduled for score 3; "the second class indicator," scheduled for score 2 and "the third class indicator," scheduled for score 1. Each item needs to record the corresponding rating value. The questionnaires were issued in 418 pieces; 403 valid pieces were collected. After sorting and filtering data, we finally obtained 289 pieces of valid questionnaires data and based on this to make validity analysis.

3.3. Reliability Analysis and Validity Analysis. SPSS17.0 is used to analyze the reliability and validity of the data. By the SPSS software's "reliability analysis" function, the reliability analysis results of all data can be obtained. $\alpha$ value is closer to 1 , the reliability is better. Use SPSS software's "factor analysis" function to precede validity analysis and get validity result of all the data, the reliability and validity of latent variables' analysis results are shown in Table 1, the reliability analysis results are shown in Table 2, and KMO and Bartlett's values are shown in Table 3.

In these tables, Cronbach's alpha coefficient is the internal consistency coefficient, which is one of the most commonly used indicators to test questionnaire's reliability, reflecting the consistency and stability degree of the scale items; Bartlett's test assumes that variable correlation coefficient matrix is the identity matrix; if the original hypothesis denied, it is suitable for factor analysis; KMO is the sampling appropriate 


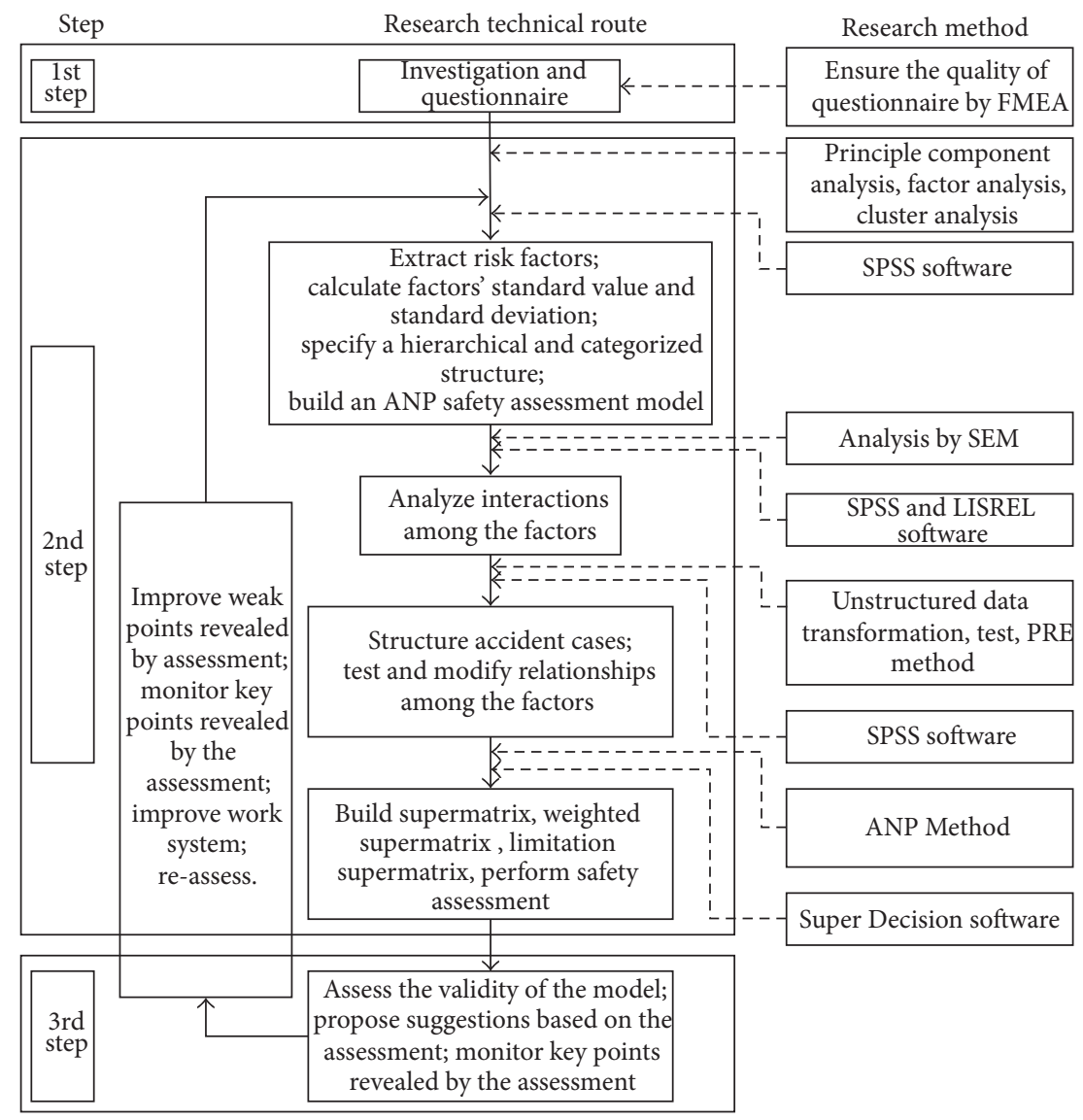

FIGURE 1: The framework of research methodology.
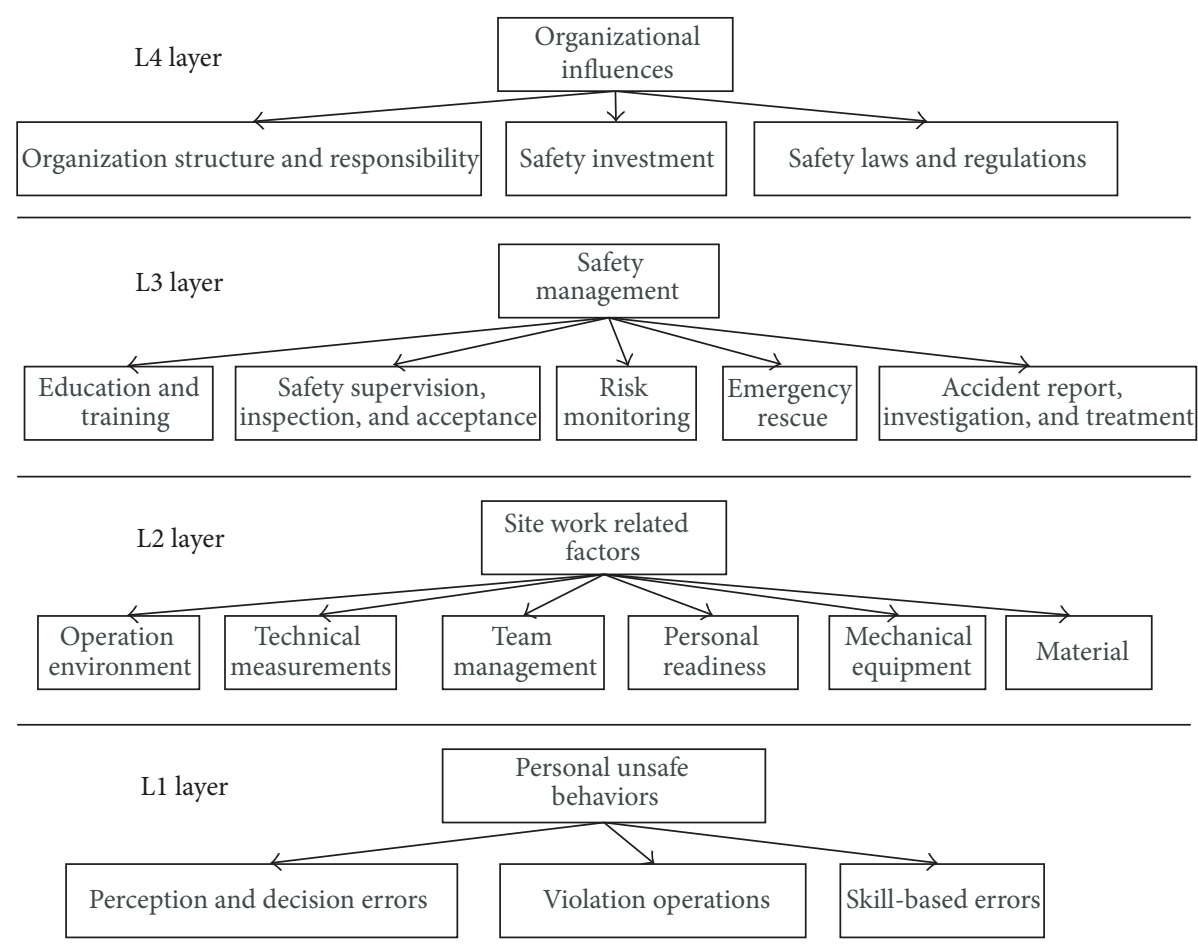

FIGURE 2: Human factors analysis and classification system framework. 
TABLE 1: The test result of latent variables' reliability and validity.

\begin{tabular}{lcccccc}
\hline \multirow{2}{*}{ Latent variable } & \multirow{2}{*}{ Measurable variables number } & \multirow{2}{*}{ KMO } & \multicolumn{2}{c}{ Bartlett's test } & \multicolumn{2}{c}{ Cronbach's alpha $(\alpha$ value $)$} \\
\hline Organizational influences & 4 & 0.675 & 177.907 & 6 & 0.000 & 0.510 \\
Safety management & 5 & 0.854 & 536.007 & 10 & 0.000 & 0.822 \\
Site work related factors & 7 & 0.918 & 1074.889 & 21 & 0.000 & 0.883 \\
Workers' unsafe behaviors & 3 & 0.727 & 342.280 & 3 & 0.000 & 0.816 \\
\hline
\end{tabular}

TABLE 2: The reliability analysis results of all data.

\begin{tabular}{lc}
\hline Cronbach's alpha ( $\alpha$ value) & Terms number \\
\hline 0.916 & 19 \\
\hline
\end{tabular}

TABLE 3: The KMO and Bartlett's test results of this study.

\begin{tabular}{lc}
\hline \multicolumn{2}{c}{ KMO and Bartlett's test } \\
\hline $\begin{array}{l}\text { Kaiser-Meyer-Olkin measurement of sampling } \\
\text { adequacy }\end{array}$ & 0.923 \\
Bartlett's test & \\
Approx. chi-square & 2924.223 \\
df & 171 \\
Sig. & 0.000 \\
\hline
\end{tabular}

parameter; this when the value is greater than 0.5 , means that these variables can make factor analysis; Sig. is significance level and less than 0.05 .

We can infer from the parameters in the table data that the value of $\alpha$ for each subscale is good, and the entire questionnaire's Cronbach's alpha coefficient reaches 0.910 , close to 1 , which indicates the high reliability of the questionnaire data. Each subscale's KMO and Bartlett's test value is good, and the entire questionnaire data's $\mathrm{KMO}$ value is 0.928 , very close to 1, Sig. $<0.05$, which shows good questionnaire construction validity. In short, the reliability and validity of the survey data are desirable.

3.4. The Factors Correlation Analysis Based on the SEM Model. Consider organizational influences as SEM model's external latent variable, the corresponding observable variables are exogenous observable variables, safety management, and the site work related factors and construction personal unsafe behaviors are latent variable, and the corresponding observable variables are endogenous observable variable. We try to establish two test models: the first model is the high layer factors which only directly affect their low layers, L4 effects on L3, L3 effects on L2, L2 effect on L1 (more accord with the HFACS theory); the second model is L3 affect L2 and L1, but L2 does not affect L1. By AMOS17.0 software, make comparison of the two models' fit indices; the fitting parameter of the first model is more satisfactory, and the first model is also more in line with the actual significance of this study. Therefore, amend the first model and make the result analysis.

Observe the M.I. value in the AMOS's output. The M.I. value is the revised index, which can discover meaningful information for improving the model's fitting situation; the correction index can predict the reduction of the chi-square value. Before the correction, we must check whether the path is correct in the model and the variable is really relevant; if the regression coefficient is significantly not equal to 0 , it represents that the path relationship between the variables is correct. When modifying the model, the higher modification index's value of the path means more conduciveness to improve the model's fitting situation.

After repeatedly estimating the model and constantly checking the output of AMOS software to find out variables with high M.I. value, simultaneously combine with the practical significance of the model to increase the correlation path. Eventually, we get the fixed model as shown in Figure 3, where the path coefficients are marked.

Model-fitted indices after being amended are shown in Table 4 . We can see that the correction model's chi-square value is reduced, the path value $\mathrm{P}$ is significantly below level 0.01 , and all fit indices have been improved greatly, explaining the model's fitting situation that getting better.

The correlation coefficient between the variables is over 0 , which means the relationship between each latent variable is positively correlated, indicating that one of the latent variables will have a positive impact on the other latent variable. Similarly, the influence between the latent variable and its corresponding observable variables is positive.

We may acquire analysis result by the AMOS that in the organizational influences layer, the safety laws and regulations' standardization path coefficient is the highest (0.799), which indicates the safety laws and regulations have a very big influence in this level. In safety management layer, emergency rescue's standardization path coefficient is the highest (0.765), followed by risk monitoring (0.755); the next is education and training (0.735). In site work related factors, team management's standardized path coefficient is 0.802 , showing the biggest influence in this layer, followed by technical measurements (0.760). In workers' unsafe behaviors layer, perception and decision errors' path coefficient is the highest (0.901); therefore, its influence is the most in this layer, followed by skill-based errors and violation operations. The interrelationship between hidden variables is different: the correlation coefficient between organizational influences and the safety management, the correlation coefficient between safety management and site work related factors, the correlation coefficient between site related factors and construction personal unsafe behaviors are, respectively, 0.872, 0.808, and 0.547; therefore, the organizational influences have the greatest impact on safety management. 


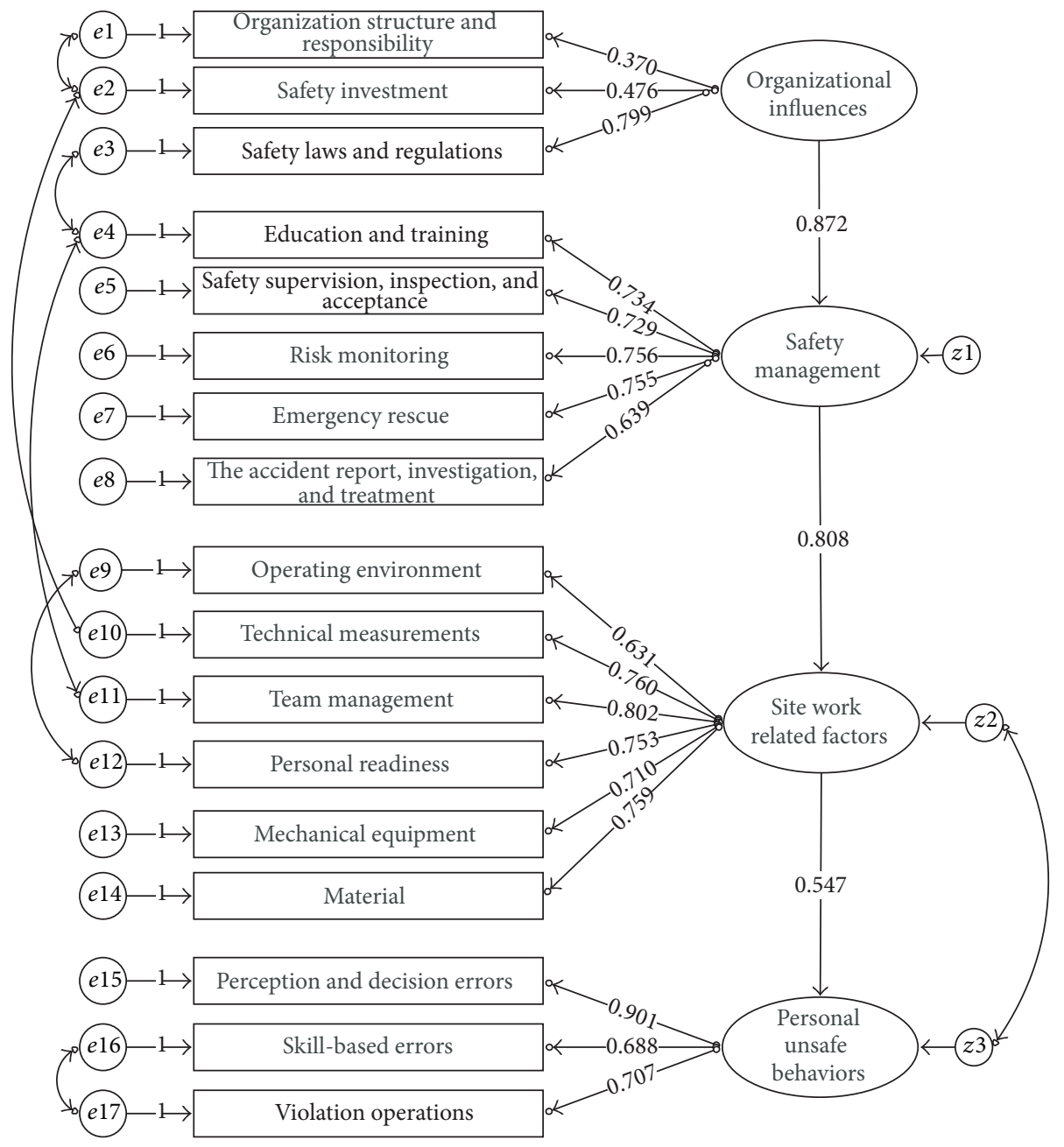

FIGURE 3: Path analysis graph for SEM revised model.

TABLE 4: Commonly used fitting index computed result of revised model.

\begin{tabular}{lccccccccccc}
\hline Fit index & Chi-square & FID & CFI & NFI & IFI & RFI & RMSEA & AIC & BCC & GFI & RMR \\
\hline Result & 181.207 & 108 & 0.970 & 0.930 & 0.970 & 0.911 & 0.049 & 271.207 & 277.207 & 0.932 & 0.124 \\
\hline
\end{tabular}

\section{The Correlation Analysis of Factors Based on Accident Cases}

Based on the accident data, we count accidents caused by human factors, find out factor categories with big proportion, and analyze their influence on accidents. The data come from "the Xiluodu project accident cases analysis," "the Xiangjiaba project accident cases analysis" and "the Three Gorges project accident cases analysis.” Apply Kappa coefficient analysis method to analyze 108 accident cases happened in the above three projects. Determining the human factors' corresponding accident cases and calculating the percentage accounted for the total number of all accidents, this study gets a general understanding of the frequency of occurrence of each factor, as well as the weighting among all the factors. The weights of human factors in Table 5 are calculated on the basis of frequency statistics of all factors resulting in the accident.
Empowering values in Table 5 will provide an important reference to build judgment matrix.

Subsequently, statistically analyze the interaction between human factors and use Chi-square test to analyze the correlation and identify the linkages between factors; apply Lambda method and Tau- $y$ method to calculate the proportional reduction in error (PRE), which is correlation analysis. Both Lambda method and Tau- $y$ method are directional statistics, and they can determine the degree of correlation between the human factors. By these methods, we find out how the factors influence each other and how to form a clue between different levels. The more detailed correlation analysis based on accident cases can be referred to in our previous work in the reference. Here, we take an example as follows: the impact of "organization structure and responsibility" on "education and training" is calculated in Table 6. When the Tau- $y$ value exceeds 0.10 , the correlation 
TABLE 5: The empowerment for each human factor.

\begin{tabular}{|c|c|c|c|c|}
\hline First class index & $\begin{array}{c}\text { Weight } \\
\text { ai }\end{array}$ & Second class index & $\begin{array}{l}\text { Weight } \\
\text { bi }\end{array}$ & $\begin{array}{c}\text { Normalized } \\
\text { weight Wi }\end{array}$ \\
\hline \multirow{3}{*}{$\begin{array}{l}\text { Organizational } \\
\text { influences L4 }\end{array}$} & \multirow{3}{*}{0.1254} & Organization structure and responsibility & 0.6019 & 0.0741 \\
\hline & & Safety investment & 0.3241 & 0.0399 \\
\hline & & Safety laws and regulations & 0.0926 & 0.0114 \\
\hline \multirow{5}{*}{$\begin{array}{l}\text { Safety } \\
\text { management L3 }\end{array}$} & \multirow{5}{*}{0.3123} & Education and training & 0.8981 & 0.1106 \\
\hline & & Safety supervision, inspection, and acceptance & 0.787 & 0.0969 \\
\hline & & Risk monitoring & 0.7222 & 0.0889 \\
\hline & & Emergency rescue & 0.0741 & 0.0091 \\
\hline & & Accident report, investigation, and treatment & 0.0556 & 0.0068 \\
\hline \multirow{6}{*}{$\begin{array}{l}\text { Site work related } \\
\text { factors L2 }\end{array}$} & \multirow{6}{*}{0.3945} & Operating environment & 0.6481 & 0.0798 \\
\hline & & Technical measurements & 0.787 & 0.0969 \\
\hline & & Team management & 0.6667 & 0.0821 \\
\hline & & Personal readiness & 0.9167 & 0.1129 \\
\hline & & Mechanical equipment & 0.1296 & 0.0160 \\
\hline & & Material & 0.0556 & 0.0068 \\
\hline \multirow{3}{*}{$\begin{array}{l}\text { Construction } \\
\text { personal unsafe } \\
\text { behaviors L1 }\end{array}$} & \multirow{3}{*}{0.1671} & Perception and decision errors & 0.5278 & 0.0645 \\
\hline & & Skill-based errors & 0.3426 & 0.0422 \\
\hline & & Violation operations & 0.4907 & 0.0604 \\
\hline
\end{tabular}

TABLE 6: The cross table of "organization structure and responsibility" on "education and training."

\begin{tabular}{lccc}
\hline Count & $\begin{array}{c}\text { q1 "organization structure and } \\
\text { responsibility" } \\
\text { Not resulting } \\
\text { in accident (0) }\end{array}$ & $\begin{array}{c}\text { Resulting in } \\
\text { accident (1) }\end{array}$ & \\
\hline $\begin{array}{l}\text { A1 “education and } \\
\text { training" } \\
\quad \begin{array}{l}\text { Not resulting in } \\
\text { accident (0) }\end{array}\end{array}$ & 10 & 1 & 11 \\
$\quad$ Resulting in accident (1) & 33 & 64 & 97 \\
\hline Sum & 43 & 65 & 108 \\
\hline
\end{tabular}

relationship is practical; when it exceeds 0.3 , the correlation relationship is strong:

$$
\begin{aligned}
E 1= & \frac{[(108-97) * 97+(108-11) * 11]}{108} \\
= & 19.759 \\
E 2= & \frac{[(43-10) * 10+(43-33) * 33]}{43} \\
& +\frac{[(65-1) * 1+(65-64) * 64]}{65}=17.318 \\
\text { Tau- } y= & \tau y=\frac{E 1-E 2}{E 1}=\frac{19.759-17.318}{19.759} \\
= & 0.124 .
\end{aligned}
$$

Based on the correlation analysis, we can draw the HFACS framework shown in Figure 4, which reflects the degree of correlation. The thick solid lines indicate strong correlation between the two factors (the Tau- $y$ value exceeds 0.1), and the dashed line indicates the weak correlation between the two factors. In Figure 4, the dashed box means the frequency of the occurring factor in the accident cases is less than 0.1 .

In Figure 4, there are some connections between the factors "organization structure and responsibility" in the L4 layer and "education training," "safety supervision, inspection, and acceptance," and "emergency rescue" in the L3 layer; the relationship between "organization structure and responsibility" and "emergency rescue" is weak, which means that safety management facilities, safety management personnel, and safe work responsibility system have limited impact on safety work emergency management and accident rescue but can greatly affect on the staff "education and training" and "safety supervision, inspection, and acceptance," which indicates that safety managers responsibilities' full fulfillments can improve the effect of safety education and training; carefully found hidden danger, strict rectification, and process monitoring can also play an important role in accident prevention.

"Education and training" in L3 layer has relationship with "team management" and "personal readiness" in L2, but the correlation with "team management" is weaker, which indicates that good safety education training of team members has a positive effect on good information communication, team cooperation, and effectiveness of foreknowing dangerous activities. The correlation between "education training" and "personal readiness" is strong, which means that "education training" can greatly improve the "personnel's basic situation"; the workers get enough safety education and skills training, which enhance their safety consciousness; they 


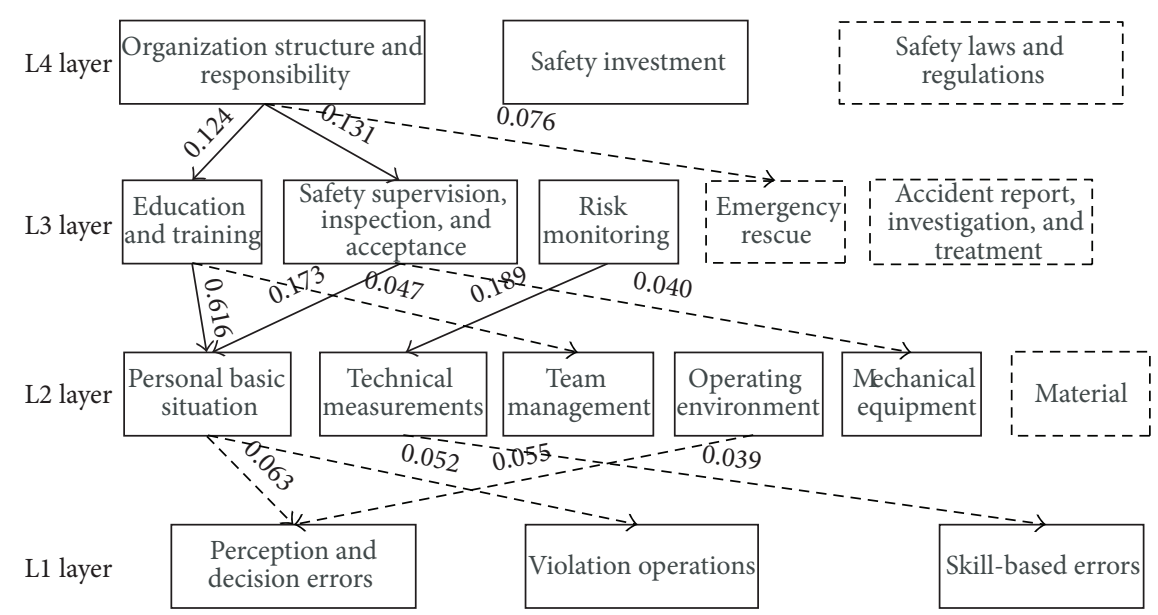

FIgURE 4: The correlation analysis among the HFACS factors using Tau- $y$ method.

also can understand their objective situation and avoid being involved in the accidents. "Safety supervision, inspection, and acceptance" in L3 layers and "personal readiness" in L2 layer as well as "mechanical equipment" have relationships, which mean "safety supervision, inspection, and acceptance" affects both the workers' situation and the mechanical equipment safety management, but less the latter. "Risk control" in L3 layer and "technical measures" in L2 layers also have relationship, which means that the dangerous places and hazards identification, assessment, and monitoring can lead to more targeted and practical measures. The premise of the safety warning signs set is the hazards identification; the rational allocation of safety measurements and confiding technical intentions are also determined by the hazards identification.

There are relationships between "operation environment" in layer 2 and "perception and decision errors" in layer 1, "technical measures" in layer 2 and "skill-based errors" in layer 1, "Personal readiness" in layer 2 and "perception and decision errors," "violation operation" in layer 1 . The dotted lines mean the relationships are weak, indicating that the construction workers' unsafe behavior is little affected by site work related conditions. The capacity of the worker's perception and decision-making, work skills, and operational violations are affected by the individual subjective, individual technical ability, and accidental factors; therefore, there are some relationships between L2 layer factors and L1 layer ones.

\section{Safety Assessment Based on the ANP Method}

5.1. Molding and Building Judgment Matrix. According to the HFACS framework as well as the mutual correlation among the human factors, build the ANP network hierarchy evaluation model, as shown in Figure 5. The model reflects the relationship between the various factors in the criterion layer.

The core work of the ANP's empowerment and solution is to compute each supermatrix, weighted super matrix, and limitation supermatrix, which is a very complex calculation process. Therefore, we use the Super Decision tool to deal with the calculation.

The judgment matrix constructed in this study is quite different from other studies. The judgment matrix is not from the expert's pairwise comparison but linearly weighs the judgment matrix $W^{\prime}$ and judgment matrix $W^{\prime \prime}$. The next both matrixes are respectively, from the pairwise comparison of empowerment values (see Table 5) and the pairwise comparison of path coefficients of structure equation modeling (see Figure 3). According to the properties of the positive reciprocal matrix, use the following formula to obtain synthetic matrix:

$$
W=\alpha W^{\prime}+(1-\alpha) W^{\prime \prime}
$$

In this formula, $\alpha$ is weighted index, $\alpha \in[0,1], W^{\prime}$ is built by the pairwise comparison of empowerment values in Table $5, W^{\prime \prime}$ is built by the pairwise comparison of path coefficients of structure equation modeling in Figure 3, and $W$ is the final judgment matrix. $W^{\prime}, W^{\prime \prime}$, and $W$ are all positive reciprocal matrixes, subjected to $a_{i j}>0, a_{i i}=$ $1, a_{i j}=1 / a_{j i}(i, j=1,2, \ldots, n)$. The judgment matrix is from concrete values compared with each other, so the judgment matrix is satisfied with $a_{i j}=a_{i k} / a_{j k}$. Each judgment matrix' consistency ratio CR is equal to zero and is satisfied with full consistency. Using the synthetic matrix, the ANP assessment process is a fully quantitative process.

The value of weighted index $\alpha$ is set to 0.7 on preference. All factors of layers with mutual relationship are carried out pair-wise comparisons. The detailed calculation process is as follows.

Firstly, build the judgment matrixes of "organizational influences," "safety management," "site work related factors" and "personal unsafe behaviors":

$$
W_{1}^{\prime}=\left[\begin{array}{cccc}
1 & 0.40 & 0.32 & 0.75 \\
2.5 & 1 & 0.79 & 1.86 \\
3.125 & 1.266 & 1 & 2.35 \\
1.33 & 0.538 & 0.426 & 1
\end{array}\right]
$$




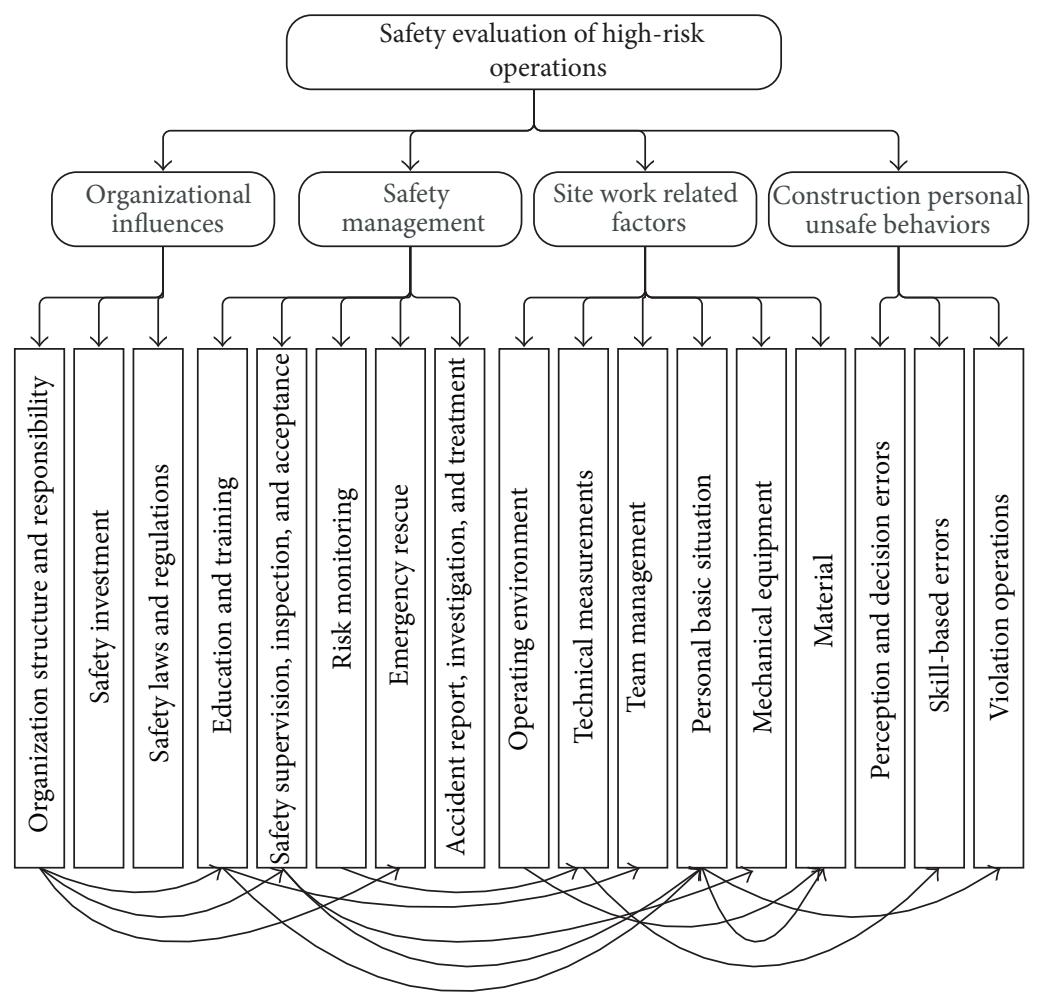

FIgURE 5: Hierarchical and correlation of the factors in ANP model.

$$
W_{1}^{\prime \prime}=\left[\begin{array}{cccc}
1 & 1.147 & 1.418 & 2.597 \\
0.872 & 1 & 1.238 & 2.262 \\
0.705 & 0.808 & 1 & 1.828 \\
0.385 & 0.442 & 0.547 & 1
\end{array}\right]
$$

According to the formula (2), the synthetic matrix is as follows:

$$
W_{1}=\left[\begin{array}{cccc}
1 & 0.62 & 0.65 & 1.30 \\
1.61 & 1 & 0.92 & 1.98 \\
1.54 & 1.09 & 1 & 2.19 \\
0.77 & 0.51 & 0.46 & 1
\end{array}\right]
$$

The judgment matrix of the elements in "organizational influences" is as follows:

$$
W_{2}=\left[\begin{array}{ccc}
1 & 1.54 & 4.69 \\
0.65 & 1 & 2.63 \\
0.21 & 0.38 & 1
\end{array}\right]
$$

The judgment matrix of the elements in "safety management" is as follows:

$$
W_{3}=\left[\begin{array}{ccccc}
1 & 1.10 & 1.16 & 8.80 & 11.73 \\
0.91 & 1 & 1.05 & 7.75 & 10.32 \\
0.86 & 0.95 & 1 & 7.14 & 9.50 \\
0.11 & 0.13 & 0.14 & 1 & 1.29 \\
0.09 & 0.10 & 0.11 & 0.78 & 1
\end{array}\right]
$$

The judgment matrix of the elements in "site work related factors" is as follows:

$$
W_{4}=\left[\begin{array}{cccccc}
1 & 0.82 & 0.92 & 0.75 & 3.76 & 8.47 \\
1.22 & 1 & 1.11 & 0.91 & 4.56 & 10.28 \\
1.09 & 0.90 & 1 & 0.83 & 3.93 & 8.77 \\
1.33 & 1.10 & 1.20 & 1 & 5.26 & 11.92 \\
0.27 & 0.22 & 0.25 & 0.19 & 1 & 1.93 \\
0.12 & 0.10 & 0.11 & 0.08 & 0.52 & 1
\end{array}\right]
$$

The judgment matrix of the elements in "personal unsafe behaviors" is as follows:

$$
W_{5}=\left[\begin{array}{ccc}
1 & 1.47 & 1.14 \\
0.68 & 1 & 0.78 \\
0.88 & 1.28 & 1
\end{array}\right]
$$

Considering correlation analysis, the judgment matrix of "organizational structure and responsibilities" to its correlation factors is as follows:

$$
W_{6}=\left[\begin{array}{ccc}
1 & 0.947 & 1.632 \\
1.056 & 1 & 1.724 \\
0.613 & 0.580 & 1
\end{array}\right]
$$

Considering correlation analysis, the judgment matrix of "education and training" to its correlation factors is as follows:

$$
W_{7}=\left[\begin{array}{cc}
1 & 0.076 \\
13.158 & 1
\end{array}\right] \text {. }
$$


TABLE 7: ANP assessment weights.

\begin{tabular}{|c|c|c|c|c|c|c|}
\hline First class index & ANP weight & Second class index & $\begin{array}{c}\text { ANP } \\
\text { weight }\end{array}$ & ANP rank & $\begin{array}{c}\text { Normalized } \\
\text { weight Wi }\end{array}$ & Cases rank \\
\hline \multirow{3}{*}{$\begin{array}{l}\text { Organizational } \\
\text { influences }\end{array}$} & \multirow{3}{*}{0.1315} & q1 organization structure and responsibility & 0.0347 & 11 & 0.0741 & 8 \\
\hline & & q2 safety investment & 0.0214 & 13 & 0.0399 & 12 \\
\hline & & $\mathrm{q} 3$ safety laws and regulations & 0.0078 & 15 & 0.0114 & 14 \\
\hline \multirow{5}{*}{$\begin{array}{l}\text { Safety } \\
\text { Management }\end{array}$} & \multirow{5}{*}{0.3474} & al education and training & 0.0693 & 6 & 0.1106 & 2 \\
\hline & & a2 safety supervision, inspection, and acceptance & 0.0652 & 7 & 0.0969 & 3 \\
\hline & & a3 risk monitoring & 0.0493 & 8 & 0.0889 & 5 \\
\hline & & a4 emergency rescue & 0.0146 & 14 & 0.0091 & 15 \\
\hline & & a5 accident report, investigation, and treatment & 0.0050 & 16 & 0.0068 & 16 \\
\hline \multirow{6}{*}{$\begin{array}{l}\text { Site work related } \\
\text { factors }\end{array}$} & \multirow{6}{*}{0.3755} & $\mathrm{xl}$ operating environment & 0.0363 & 10 & 0.0798 & 7 \\
\hline & & $\mathrm{x} 2$ technical measurements & 0.0934 & 5 & 0.0969 & 4 \\
\hline & & x3 team management & 0.0440 & 9 & 0.0821 & 6 \\
\hline & & $\mathrm{x} 4$ personal readiness & 0.1664 & 1 & 0.1129 & 1 \\
\hline & & x5 mechanical equipment & 0.0216 & 12 & 0.0160 & 13 \\
\hline & & $\mathrm{x} 6$ material & 0.0044 & 17 & 0.0068 & 17 \\
\hline \multirow{3}{*}{$\begin{array}{l}\text { Construction } \\
\text { personal unsafe } \\
\text { behaviors }\end{array}$} & \multirow{3}{*}{0.1456} & $\mathrm{~d} 1$ perception and decision errors & 0.1551 & 2 & 0.065 & 9 \\
\hline & & d2 skill-based errors & 0.1122 & 3 & 0.0422 & 11 \\
\hline & & $\mathrm{d} 3$ violation operations & 0.0994 & 4 & 0.0604 & 10 \\
\hline
\end{tabular}

Considering correlation analysis, the judgment matrix of "safety supervision, inspection, and acceptance" to its correlation factors is as follows:

$$
W_{8}=\left[\begin{array}{cc}
1 & 4.325 \\
0.231 & 1
\end{array}\right] .
$$

Considering correlation analysis, the judgment matrix of "personal basic situation" to its correlation factors is as follows:

$$
W_{9}=\left[\begin{array}{cc}
1 & 1.212 \\
0.825 & 1
\end{array}\right]
$$

According to Figure 5, we use SD tool to build the ANP model. The model reflects the relationship between the variables in the layer factors. At the network layer, we have four categories; each category has several elements (17 evaluation indicators in the sum). Because the factors in the layers are not independent, the circular arrow lines are seen in Figure 5.

5.2. Solutions. Through calculation by the SD software, the weight values of every factor are shown in Table 7.

5.3. Results. In Table 7, the four smallest weight values of the factors are, respectively, "material" (0.0044), "accident report, investigation and treatment" (0.0050), "safety laws and regulations" (0.0078), and "emergency rescue" (0.0146). The normalized weight values based on cases statistics also show that these four factors result in accidents less frequently, which indicate that these four factors less likely to result in accidents in the high-risk construction operations, and the organizations have done well in these four aspects.
The four greatest weight values of the factors are, respectively, "personal readiness" (0.1664), "perception and decision errors" (0.1551), "skill-based errors" (0.1122), and "violation operations" (0.0994). But in of cases statistical analysis, the four greatest weight values are "personal readiness"(0.1129), "education training" (0.1106), "technical measures" (0.0969), and "safety supervision, inspection, and acceptance" (0.0969). Only "personal readiness" is the most greatest in both methods, which shows that in the project construction, when the worker's basic situation greatly influences his safety consciousness, risk awareness, and psychological and physiological conditions. In order to guarantee the safety of construction projects, organizations should strive to improve this factor. The rank of "educating training" drops from the original 2 to 6 , indicating that the interaction among the factors will lead to the assessment results change. Because the "education and training" and "personal readiness" have a very strong relationship, the imperfections of the safety education and skills training will lead to personnel's basic situation get worse. In order to avoid the double counting of the associated factors, the assessment weight of "education and training" decreases. The weight of "safety supervision, inspection, and acceptance" drops from the original ranking 3 to 7 , which is a result that this factor also directly affects "personal readiness." So with the similar reason, the ANP assessment weight of "safety supervision, inspection, and acceptance" decreases.

After ANP assessment, the weight values of "perception and decision errors," "skill-based errors," and "operation violation" have increased. According to the results of factor analysis, "education training" and "safety supervision, inspection, and acceptance" will influence "personal readiness," "personal readiness" located in L2 layer directly influences "perception and decision-making errors" in L1 layer 
and "operation violation," and "risk monitoring" influences "technology measures," "technology measures" in L2 layer influence "skills errors" in L1 layer. It can be seen that construction worker's unsafe behavior is the direct influential factor which may lead to the accident. Three factors in L1 layer "perception and decision-making errors," "skill errors," and "operation irregularities" with higher weight values in ANP assessment, which also indicate the unsafe behavior of construction workers, are the most important factors leading to accidents.

In "organizational influences" layer, the three factors of "organization structure and duties," "safety investments," and "safety laws and regulations," their weight values being relatively smaller, indicate that the organizations have taken complete measurements on these aspects, have invested on safety management institutions, safety management personnel, and have established the safety work responsibility system, series of laws and regulations, and relevant rules and regulations. All the above measures are successful.

In the actual construction project, these 17 assessment factors often influence each other, so the ANP assessment results may be more realistic and can provide a reference for the engineering and construction management. Meanwhile, there are still a lot of factors need to be considered to determine the final management plans and schedules.

\section{Conclusions}

This study firstly revises the standard HFACS framework to evaluate the risk factors of the high-risk operations in hydroelectric engineering construction, constructs a comprehensive framework system from the organizational layer to personal layer, and is based on the framework to deal with the subsequent research.

Secondly, this study obtains the original data from questionnaire and analyzes the data by the SPSS. The reliability and validity analysis results indicate that the questionnaire data met the realistic requirements. The conceptual model is drawn by AMOS, the raw data is imported from the SPSS to fit, make comparison, revise, and analyze the model. After modeling, analyzing, and revising, we get correlation coefficients between latent variables which may influence hydroelectric construction safety as well as correlation coefficients between latent variables and their corresponding observable variables. The correlation coefficients excess zero, which means the variables have positive relationships; if any variable (factor) is improved, other variables (factors) will also be improved to some degree. The value of correlation coefficient between variables shows the influence on each other. These results give some reference for the organizations to develop management regulations and strategies.

Thirdly, we use the statistical methods such as the PRE method, revise HFACS framework to analyze 108 accident cases, and count the frequency of each risk factor in the accidents. We use the chi-square test to determine correlation between adjacent level factors, in order to determine the concrete association degree between the factors more accurately and calculate the correlation coefficient with the PRE method between the factors. The coefficient values indicate the correlation degree between the two factors.

Finally, we use the ANP method to evaluate the importance of the factors influencing safety work. The traditional safety assessment methods generally use subjective qualitative or semiqualitative principles; not quantitatively assess the safety and risk of construction project. The AHP method cannot consider the interrelationship between the factors they do and is not consistent with the actual situation. However, the ANP method makes up for such deficiency. In this study, the ANP model's judgment matrix is not from the pair-wise comparison method, but from a combination of accident cases analysis results of factor frequency, the correlation coefficient between the factors, and the path coefficient of structural equation modeling. Then, we follow a linear formula to get the final judgment matrix, which can improve the qualitative analysis result relative to the traditional ANP method (the expert rating). Such method makes possible the assessment results more objective and quantitative.

Due to research limitation, there remains a further analysis to satisfy a more realistic factors classification and hierarchical relationships as well as more rational framework. The accident cases data are also limited and cannot cover all characteristics of risk factors. The analysis model is to some extent simple, according to a fixed direction to make factor analysis, and the variables in the analysis process are nominal variables. However, in the actual construction project, the relationships between the factors are complex; there are no such simple relationships in the HFACS model. Therefore, there may some deviations between the analysis results and the realistic situation.

Finally, this study only selects structural equation modeling, accidents statistical analysis, and ANP method to implement the safety assessment research and has not comprehensively compared other more methods, such as Bayesian theory, D-S evidence theory, and neural network. Therefore, the assessment results may not be most accurate and optimal. As a result, we should carry out a variety of assessment methods and select the combination of optimal methods to evaluate in the future.

\section{Conflict of Interests}

The authors declare that there is no conflict of interests regarding the publication of this paper.

\section{Acknowledgments}

This paper is supported by the National Natural Science Fund Project (50909045, 51079078), and the Fundamental Research Funds for the Central Universities (HUST: 2013QN154).

\section{References}

[1] D. A. Wiegmann and S. A. Shappell, "Human error analysis of commercial aviation accidents: application of the human factors 
analysis and classification system (HFACS)," Aviation Space and Environmental Medicine, vol. 72, no. 11, pp. 1006-1016, 2001.

[2] J. Reason, Human Error, Cambridge University Press, New York, NY, USA, 1990.

[3] M. G. Lenné, P. M. Salmon, C. C. Liu, and M. Trotter, "A systems approach to accident causation in mining: an application of the HFACS method," Accident Analysis and Prevention, vol. 48, pp. 111-117, 2012.

[4] J. M. Patterson and S. A. Shappell, "Operator error and system deficiencies: analysis of 508 mining incidents and accidents from Queensland, Australia using HFACS," Accident Analysis and Prevention, vol. 42, no. 4, pp. 1379-1385, 2010.

[5] H. S. J. Rashid, C. S. Place, and G. R. Braithwaite, "Helicopter maintenance error analysis: beyond the third order of the HFACS-ME," International Journal of Industrial Ergonomics, vol. 40, no. 6, pp. 636-647, 2010.

[6] M. Celik and S. Cebi, "Analytical HFACS for investigating human errors in shipping accidents," Accident Analysis and Prevention, vol. 41, no. 1, pp. 66-75, 2009.

[7] C. Chauvin, S. Lardjane, G. Morel, and J. P. Clostermann, "Human and organizational factors in maritime accidents: analysis of collisions at sea using the HFACS," Accident Analysis and Prevention, vol. 59, pp. 26-37, 2013.

[8] S. Reinach and A. Viale, "Application of a human error framework to conduct train accident/incident investigations," Accident Analysis and Prevention, vol. 38, no. 2, pp. 396-406, 2006.

[9] A. W. ElBardissi, D. A. Wiegmann, J. A. Dearani, R. C. Daly, and T. M. Sundt III, "Application of the human factors analysis and classification system methodology to the cardiovascular surgery operating room," Annals of Thoracic Surgery, vol. 83, no. 4, pp. 1412-1419, 2007.

[10] T. F. Golob, "Structural equation modeling for travel behavior research," Transportation Research B, vol. 37, no. 1, pp. 1-25, 2003.

[11] P. K. Marhavilas and D. Koulouriotis, "Risk Estimation in the Constructions' Worksites by using a Quantitative Assessment Technique and Statistical Information of Accidents," Scientific Journal of Technical Chamber of Greece, vol. 1, no. 1-2, pp. 47-60, 2007.

[12] P. K. Marhavilas and D. E. Koulouriotis, "A risk-estimation methodological framework using quantitative assessment techniques and real accidents' data: application in an aluminum extrusion industry," Journal of Loss Prevention in the Process Industries, vol. 21, no. 6, pp. 596-603, 2008.

[13] P. K. Marhavilas, D. E. Koulouriotis, and K. Voulgaridou, "Development of a quantitative risk assessment technique and application on an industry's worksite using real accidents' data," Scientific Journal of Hellenic Association of Mechanical and Electrical Engineers, vol. 416, pp. 14-20, 2009.

[14] H. Chen, H. Qi, O. Wang, and R.-Y. Long, "The research on the structural equation model of affecting factors of deliberate violation in coalmine fatal accidents in China," System Engineering Theory and Practice, vol. 27, no. 8, pp. 127-136, 2007.

[15] K. J. Graham and G. F. Kinney, "Explosive shocks in air," Journal of the Acoustical Society of America, vol. 80, no. 2, pp. 708-709, 1986.

[16] Peng Dongzhi, "Four dangers condition identification and control in water and electricity project construction work system," Construction Technique, vol. 26, no. 5, pp. 70-72, 2007.
[17] N. Dedobbeleer and F. Béland, "A safety climate measure for construction sites," Journal of Safety Research, vol. 22, no. 2, pp. 97-103, 1991.

[18] K. Øien, "Risk indicators as a tool for risk control," Reliability Engineering and System Safety, vol. 74, no. 2, pp. 129-145, 2001.

[19] K. Øien, "Risk indicators as a tool for risk control," Reliability Engineering and System Safety, vol. 74, no. 2, pp. 147-167, 2001.

[20] M. Daǧdeviren, I. Yüksel, and M. Kurt, "A fuzzy analytic network process (ANP) model to identify faulty behavior risk (FBR) in work system," Safety Science, vol. 46, no. 5, pp. 771$783,2008$.

[21] E. Ai Lin Teo and F. Yean Yng Ling, "Developing a model to measure the effectiveness of safety management systems of construction sites," Building and Environment, vol. 41, no. 11, pp. 1584-1592, 2006.

[22] D. Zhong, S. Cai, and Y. Li, "Risk analysis of hydropower project based on analytic network process and its application," Journal of Hydroelectric Engineering, vol. 27, no. 1, pp. 11-17, 2008.

[23] Z. Ayağ and R. G. Özdemir, "A hybrid approach to concept selection through fuzzy analytic network process," Computers and Industrial Engineering, vol. 56, no. 1, pp. 368-379, 2009.

[24] K. F. R. Liu and J.-H. Lai, "Decision-support for environmental impact assessment: a hybrid approach using fuzzy logic and fuzzy analytic network process," Expert Systems with Applications, vol. 36, no. 3, pp. 5119-5136, 2009.

[25] J. S. Ha and P. H. Seong, "A method for risk-informed safety significance categorization using the analytic hierarchy process and bayesian belief networks," Reliability Engineering and System Safety, vol. 83, no. 1, pp. 1-15, 2004.

[26] D. Vujanović, V. Momčilović, N. Bojović, and V. Papić, "Evaluation of vehicle fleet maintenance management indicators by application of DEMATEL and ANP," Expert Systems with Applications, vol. 39, no. 12, pp. 10552-10563, 2012.

[27] H.-T. Liu and Y.-L. Tsai, "A fuzzy risk assessment approach for occupational hazards in the construction industry," Safety Science, vol. 50, no. 4, pp. 1067-1078, 2012. 


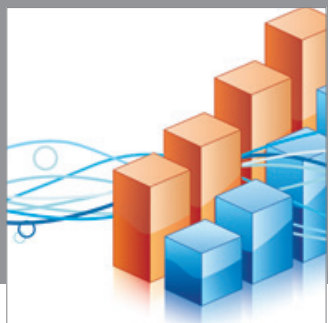

Advances in

Operations Research

mansans

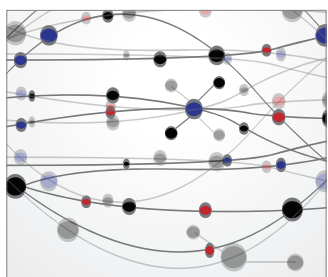

The Scientific World Journal
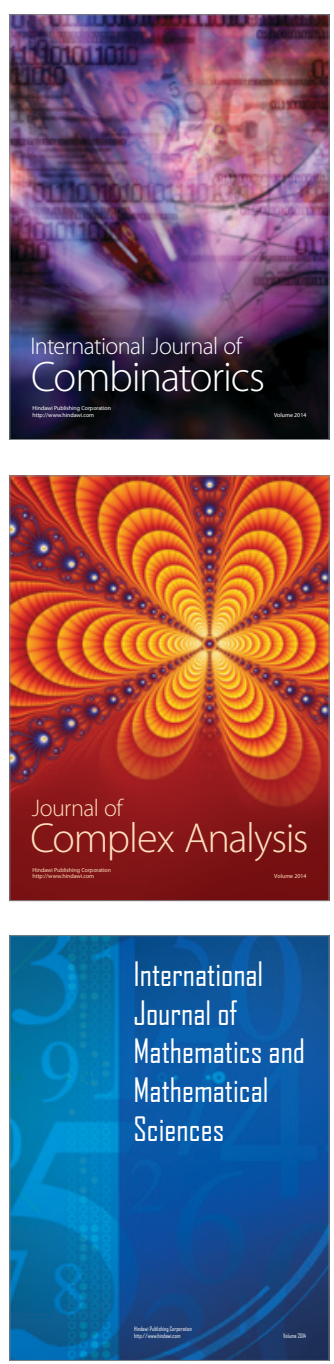
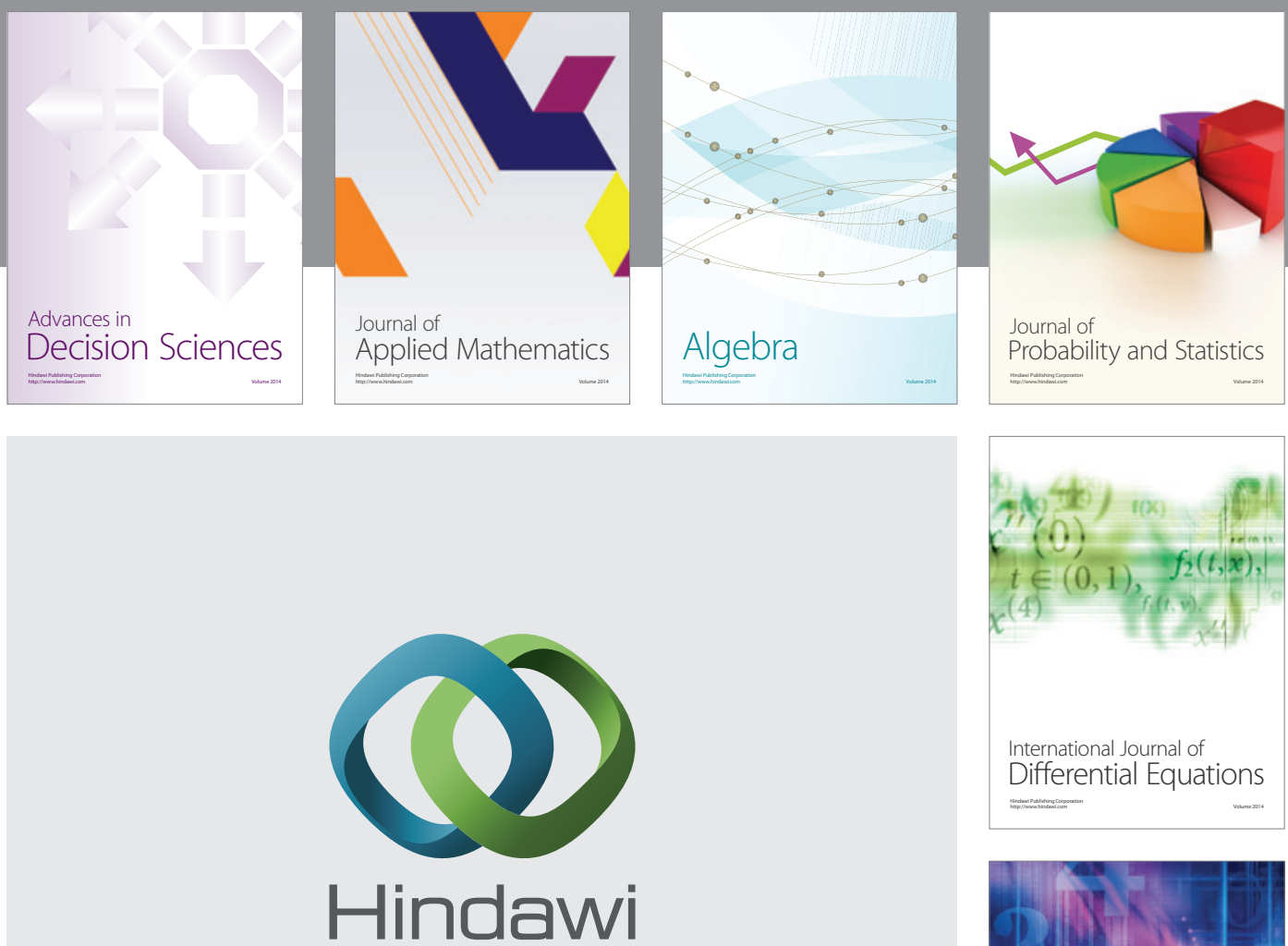

Submit your manuscripts at http://www.hindawi.com
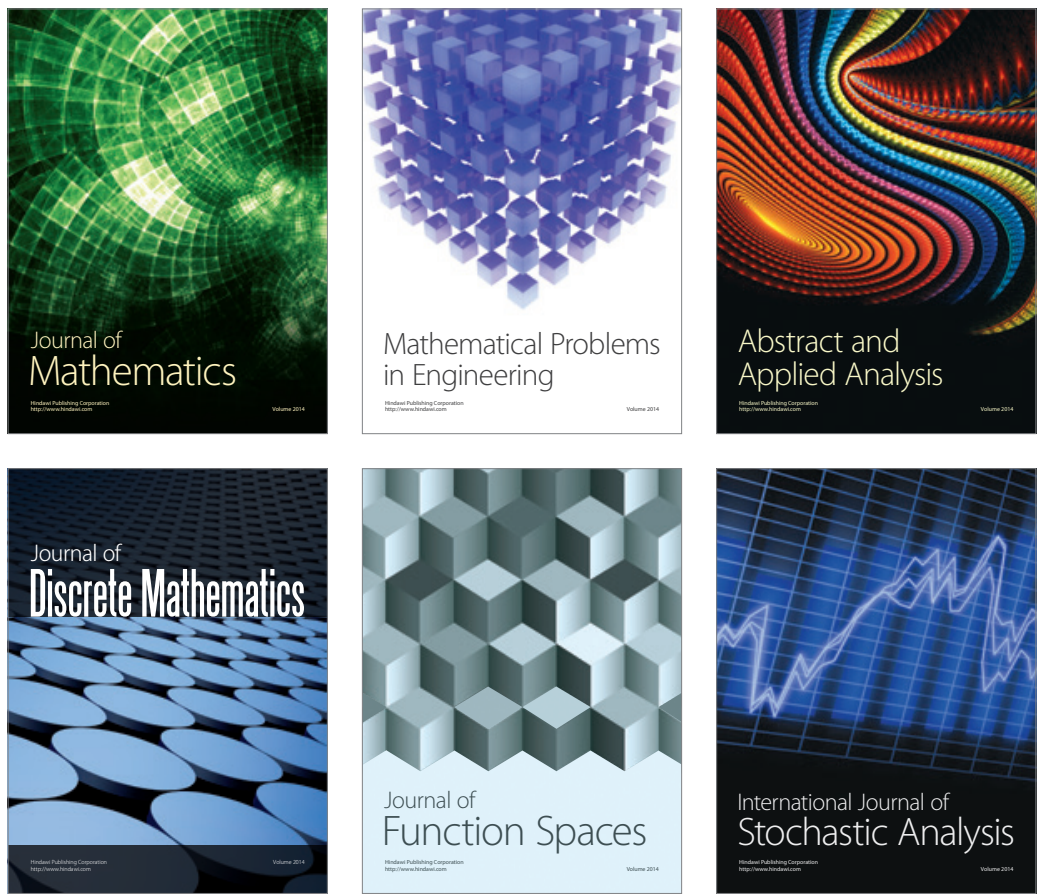

Journal of

Function Spaces

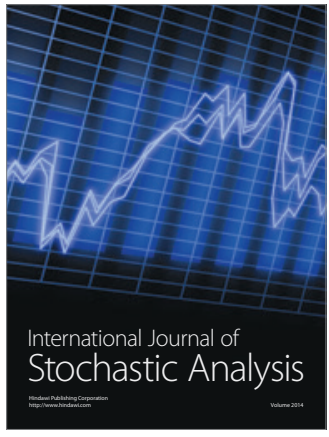

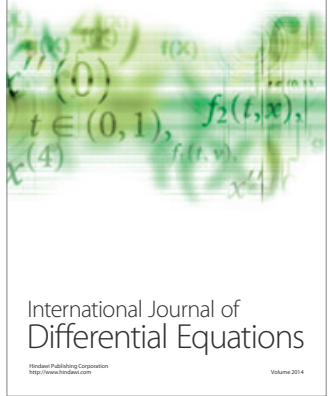
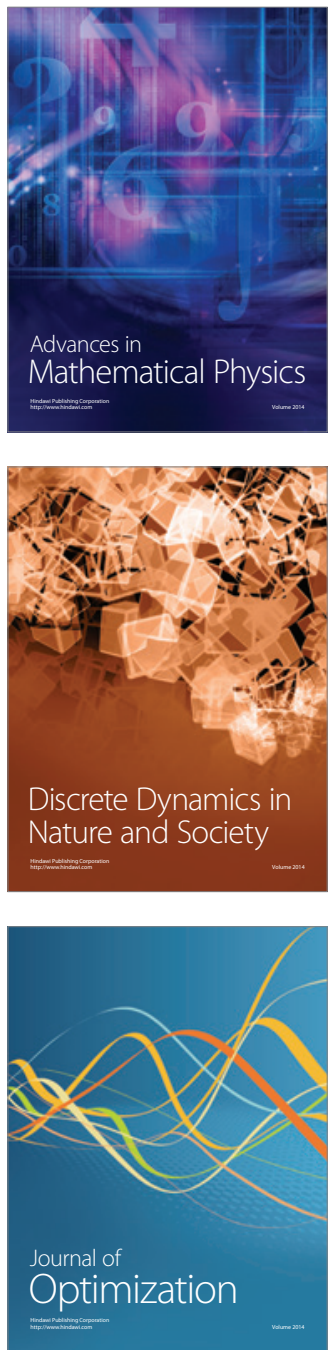